\title{
Morphology, thermal, electrical and electrochemical stability of nano aluminium-oxide-filled polyvinyl alcohol composite gel electrolyte
}

\author{
NAVIN CHAND, NEELESH RAI ${ }^{\dagger} *$, S L AGRAWAL ${ }^{\dagger}$ and S K PATEL ${ }^{\dagger}$ \\ Advanced Materials and Processes Research Institute (AMPRI), (Formerly RRL) (CSIR) Habibganj Naka, \\ Bhopal, India \\ ${ }^{\dagger}$ SSI Laboratory, Department of Physics, APS University, Rewa, Madhya Pradesh, India
}

MS received 27 May 2010; revised 10 February 2011

\begin{abstract}
In the present work, an attempt has been made to develop nano aluminium oxide $\left(\mathrm{Al}_{2} \mathrm{O}_{3}\right)$-filled polyvinyl alcohol (PVA) composite gel electrolytes. Surface morphological studies, thermal behaviour, electrochemical stability and electrical characterization of these composite gel electrolytes have been performed. An increase in the concentration of $\mathrm{Al}_{2} \mathrm{O}_{3}$ in composite gel electrolytes increases the amorphous characteristics of pure PVA. Bulk conductivity of composite gel electrolytes increases by an order of magnitude on addition of a nano filler. Maximum conductivity of $5.81 \times 10^{-2} \mathrm{~S} / \mathrm{cm}$ is observed for $6 \mathrm{wt} \% \mathrm{Al}_{2} \mathrm{O}_{3}$-filled polymer gel composite electrolytes. Temperature dependence of electrical conductivity shows a combination of Arrhenius and Vogel-Tamman-Fulcher (VTF) nature. Maximum current stability during oxidation and reduction cycle is noticed for $6 \mathrm{wt} \% \mathrm{Al}_{2} \mathrm{O}_{3}$-filled PVA composite electrolyte, viz. $\pm 1.65 \mathrm{~V}$.
\end{abstract}

Keywords. Polymer nanocomposite gel electrolytes; ionic conductivity; polymer electrolytes; X-ray diffraction; differential scanning calorimetry.

\section{Introduction}

Polymer electrolytes have become materials of great importance for use in different electrochemical devices due to their unique characteristics such as easy mouldabality, good electrode-electrolyte contact and light weight (MacCallum and Vincent 1989; Gray 1991). These polymer electrolytes form a bridge between liquid electrolyte and solvent-free ceramics (Scrosati and Vincent 2000). Because of their high ionic conductivity, gel electrolytes have attained precedence over conventional polymer electrolytes. In recent years, polymethylmethacrylate (PMMA) (Bohnke et al 1992; Sekhon 2003; Singh et al 2005), polyacrylonitrile (PAN) (Croce et al 1994), polyvinylidenefluoride (PVdF) (Song et al 2000; Sekhon 2003) and polyethylene oxide (PEO) (Radhucha et al 1996; Sekhon 2003) have been reported as suitable polymer host material for the preparation of polymer gel electrolytes.

Literature survey has revealed that most of the work reported on polymer gel electrolytes concerns development of lithium-based polymer batteries (Koksbang et al 1994; Caravanier et al 2003; Sekhon 2003; Sato et al 2005). Proton conductors are equally important class of electrolyte materials due to their applications in fuel cells, electrochromic devices (ECDs) and other smart devices

\footnotetext{
*Author for correspondence (neeleshssi@gmail.com)
}

(Colomban 1992). Within the family of proton conductors, work on PEO-based gel electrolytes with strong acids like $\mathrm{H}_{3} \mathrm{PO}_{4}, \mathrm{H}_{2} \mathrm{SO}_{4}$ and $\mathrm{HCl}$ (Wieczorek et al 1995; Radhucha et al 1996), and PMMA-based gel electrolytes containing benzoic and dicarboxylic acids (Chandra et al 2000; Song et al 2000; Sekhon et al 2002; Sekhon 2003) have been reported in recent years. Within the umbrella of polymer gel electrolytes, PVA is also one of the prominent polymers because of its good solvent holding capability and wide temperature window (Finch 1973). Moreover, it is known to form a good gel material for medical applications (Cavalieri et al 2003). Awadhia and Agrawal (2007) have reported PVA-based protonconducting gel electrolyte with high ionic conductivity. However, when most of the studied gel electrolytes are retained for a long period, exudation of liquid from gel lump occurs, which causes instability in device performance. As synthesized gel electrolytes of polyvinyl alcohol: dimethyl sulphoxide: ammonium thiocynate (PVA: DMSO : $\mathrm{NH}_{4} \mathrm{SCN}$ ) also show similar behaviour with aging (Awadhia and Agrawal 2007), which limits its utility in practical devices when operated over long periods. Therefore, with anticipation of better stability under ambient conditions such as-synthesized gel electrolytes are usually doped with inorganic/organic fillers leading to the formation of composite gel electrolytes (Honma et al 1999; Ray and Okomota 2003; Koo 2006; Agrawal and Pandey 2008; Duangkaew and Woothikanokkhan 2008). A similar approach has been tried in the present work to 
improve the performance of PVA:DMSO : $\mathrm{NH}_{4} \mathrm{SCN}$ electrolytes by dispersal of nano-sized $\mathrm{Al}_{2} \mathrm{O}_{3}$ filler particles. This system is expected to drastically impede crystallization process in polymer-based nanocomposite electrolytes and thus improve ionic conductivity, mechanical integrity as well as its electrochemical stability for long-term use in electrochemical devices, particularly smart windows, owing to the possibility of single ion conduction (Agrawal and Shukla 2000). Freestanding films were prepared by conventional solution cast technique and subsequently characterized by X-ray diffraction (XRD), differential scanning calorimetry (DSC), cyclic voltammetry $(\mathrm{CV})$ and conductivity measurements.

\section{Experimental}

In the present investigation, PVA (average molecular weight 124,000-186,000; Aldrich make), ammonium thiocyanate $\left(\mathrm{NH}_{4} \mathrm{SCN}\right), \mathrm{AR}$ grade (s.d. fine chem make) and aprotic solvent dimethyl sulphoxide (DMSO) (Merk Limited, Mumbai) were used for synthesis of composite gels. $\mathrm{Al}_{2} \mathrm{O}_{3}$ used in the study was obtained from Alfa Aesar, CAS Number: 1344-28-1 and the size of the particles was between 40 and $50 \mathrm{~nm}$. PVA was dispersed in $1 \mathrm{M}$ salt solution of $\mathrm{NH}_{4} \mathrm{SCN}$ in DMSO in different stoichiometric ratios to form pristine gel electrolyte (PVA : $\mathrm{NH}_{4} \mathrm{SCN}$ system). Composite polymer gel electrolytes were prepared by adding $\mathrm{Al}_{2} \mathrm{O}_{3}$ nanoparticles in pristine gel electrolyte solution in different weight proportions followed by thorough mixing at slightly elevated temperature on a magnetic stirrer. The so-formed solutions were poured in $\mathrm{PC}$ petri dishes and covered with $\mathrm{Al}$ foils to avoid contamination. After syneresis, gels in the form of thick films were taken out and dried at room temperature for few a days to obtain stable gel electrolytes. The resulting gel films were stored carefully to avoid exudation of solvent. Structural morphology of different polymer nanocomposite electrolytes were studied by X-ray diffractometer (model no. RIGAKU JAPAN MINIFLEX-II). The diffraction pattern was recorded at room temperature $\left(\sim 25^{\circ} \mathrm{C}\right)$ for the Bragg angles $(2 \theta)$ varying from $2^{\circ}$ to $90^{\circ}$ with the scan speed of $2 \mathrm{~min}^{-1}$. SEM images of different polymer nanocomposite electrolyte system were recorded with JEOL JSM-6390A instrument. The complex-impedance measurements were carried out with help of a computer-controlled Hioki (Japan) make LCR meter (Model 3520). After sandwiching the composite gel electrolytes sample between two platinum electrodes, electrical conductivity measurements were performed in the frequency range varying from $40 \mathrm{~Hz}$ to $100 \mathrm{kHz}$ at various temperatures ranging between 300 and $373 \mathrm{~K}$. The thermal behaviour of $\mathrm{Al}_{2} \mathrm{O}_{3}$ nanoparticle-filled PVA gel electrolytes were observed using a Mettler Toledo DSC model 822e. Differential scanning calorimetry (DSC) runs were recorded at $10^{\circ} \mathrm{C} \min ^{-1}$ heating rates for unfilled and 2, 4, $6 \mathrm{wt} \%$ nanoparticle $\left(\mathrm{Al}_{2} \mathrm{O}_{3}\right)$-filled PVA gel electrolytes. The DSC scans of these samples were carried out only to measure glass temperature $\left(T_{\mathrm{g}}\right)$ and melting temperature $\left(T_{\mathrm{m}}\right)$ in the temperature range $40-240^{\circ} \mathrm{C}$. Cyclic voltammetry analysis was carried out in air at room temperature using an Electrochemical Analyzer ( $\mathrm{CH}$ Instruments, USA model no. CHI608D) in the voltage sweep range $\pm 3 \mathrm{~V}$ keeping the scan rate at $0 \cdot 1 \mathrm{~V} \mathrm{~s}^{-1}$. Current-time measurements on the samples were conducted to estimate ionic transference number and nature of charge transport.

\section{Results and discussion}

\subsection{Morphology studies}

Figures 1a-d depicts the surface morphology of DMSO : $\mathrm{NH}_{4} \mathrm{SCN}$ : PVA electrolyte films containing 0, 2, 6 and $10 \mathrm{wt} \%$ concentration of $\mathrm{Al}_{2} \mathrm{O}_{3}$ nanofiller. Unfilled PVA gel electrolyte shows a closed pore structure made up of PVA chains. Addition of $2 \mathrm{wt} \% \quad \mathrm{Al}_{2} \mathrm{O}_{3}$ nanoparticles reduces the porosity of PVA composite electrolyte because $\mathrm{Al}_{2} \mathrm{O}_{3}$ nano particles are entrapped between chains in the pores (figure 1b). White coloured spots observed in the SEM image show that $\mathrm{Al}_{2} \mathrm{O}_{3}$ nanofiller particles are not fully absorbed. On addition of $6 \mathrm{wt} \% \quad \mathrm{Al}_{2} \mathrm{O}_{3}$ nano particles (figure 1c), chains of PVA are fully covered with $\mathrm{Al}_{2} \mathrm{O}_{3}$ nanoparticles. This indicates complete dispersion of $\mathrm{Al}_{2} \mathrm{O}_{3}$ nanofiller in electrolyte film. On further addition of $\mathrm{Al}_{2} \mathrm{O}_{3}$ nanoparticles in the system, separate grains comprising of $\mathrm{Al}_{2} \mathrm{O}_{3}$ nanoparticles and PVA electrolyte are formed. Grains are of irregular size and shape, confirming its partial crystalline texture.

\subsection{XRD studies}

The XRD patterns of polymer gel electrolytes films of DMSO : $\mathrm{NH}_{4} \mathrm{SCN}$ : PVA without and with $\mathrm{Al}_{2} \mathrm{O}_{3}$ nanofillers along with pristine materials are shown in figure $2 \mathrm{a}-\mathrm{h}$. These patterns show an increase in amorphousity of polymer electrolyte after addition of salt and $\mathrm{Al}_{2} \mathrm{O}_{3}$ nanofiller. The intense XRD pattern for DMSO casted PVA film (figure 2c) exhibits a moderately broad peak around $19 \cdot 6^{\circ} \mathrm{C}$, which shifts to lower $2 \theta$ value in PVA: $\mathrm{NH}_{4} \mathrm{SCN}$ : DMSO (figure 2d) gel electrolyte. Recently, this shifting of PVA-related peak has been correlated to complexation of pristine components leading to the formation of polymer gel electrolyte (Awadhia and Agrawal 2007). Upon addition of $\mathrm{Al}_{2} \mathrm{O}_{3}$ nanofiller, the peak broadens and shifts toward higher $2 \theta$ values. Further, no peak related to $\mathrm{Al}_{2} \mathrm{O}_{3}$ (figure $2 \mathrm{a}$ ) could be tracked. This feature ascertains improvement in system morphology with complete absorption of $\mathrm{Al}_{2} \mathrm{O}_{3}$ particles in the PVA matrix. At higher concentrations of $\mathrm{Al}_{2} \mathrm{O}_{3}$, the characteristic reflections of $\mathrm{Al}_{2} \mathrm{O}_{3}$ nanofiller start reappearing 

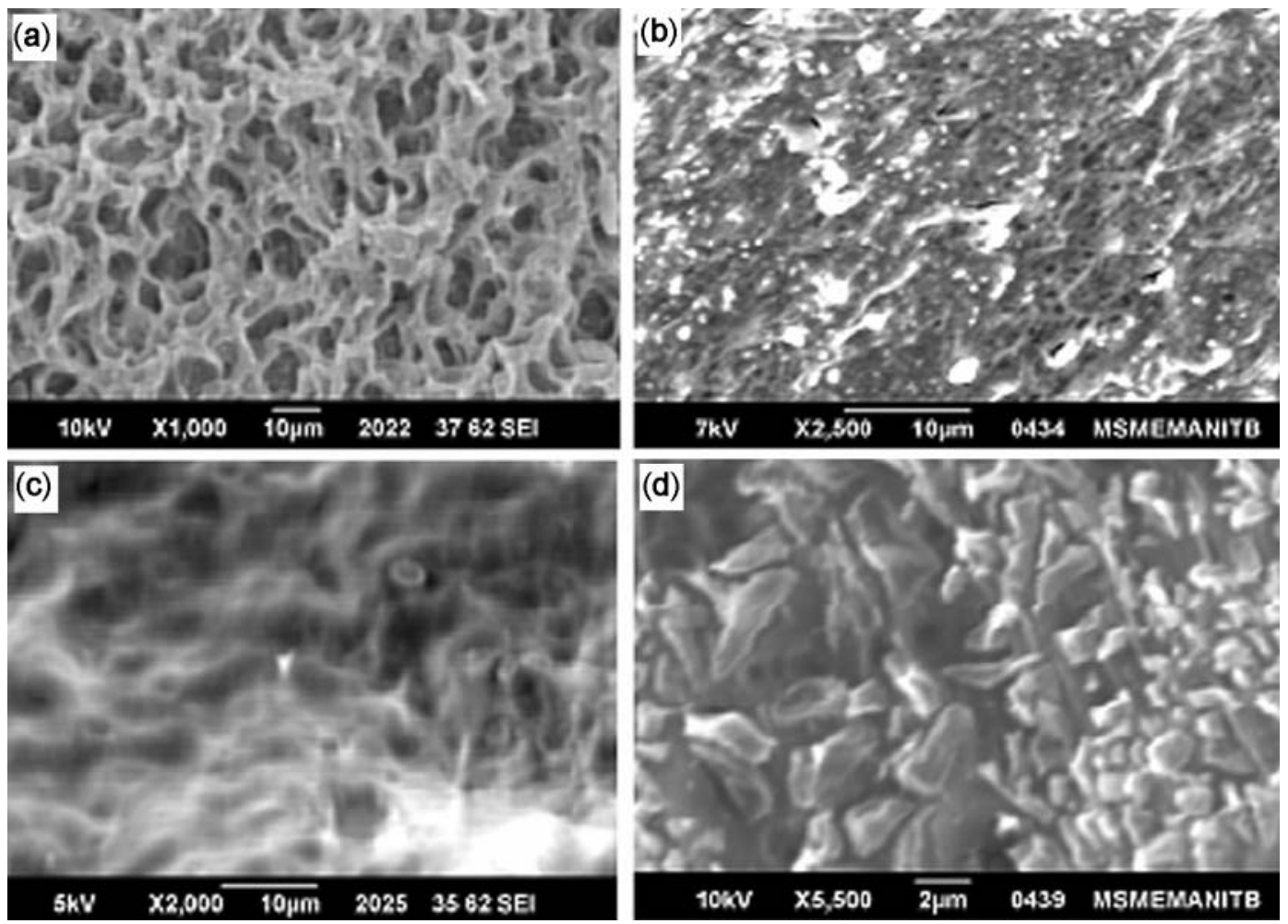

Figure 1. SEM images of (a) DMSO casted PVA : $\mathrm{NH}_{4} \mathrm{SCN}$ gel electrolyte and its composite containing (b) $2 \mathrm{wt} \%$, (c) $6 \mathrm{wt} \%$ and (d) $10 \mathrm{wt} \% \mathrm{Al}_{2} \mathrm{O}_{3}$ filler.

because of its segregation. From the XRD study, it is concluded that $\mathrm{Al}_{2} \mathrm{O}_{3}$ nanofillers are homogenously dispersed throughout the polymer matrix with maximum uptake of $6 \mathrm{wt} \%$. The strong and sharp diffraction peaks in $\mathrm{Al}_{2} \mathrm{O}_{3}$ and $\mathrm{NH}_{4} \mathrm{SCN}$ indicate high crystallinity of the obtained products, which disappears in case of polymer composites due to enhancement in amorphous nature of electrolytes. Degree of crystallinity, $X_{\mathrm{c}}$ of electrolytes with respect to $\mathrm{Al}_{2} \mathrm{O}_{3}$ was estimated to ascertain improvement in amorphous nature (Cullity 1978) presuming the filler to be fully crystalline (table 1). Likewise, the average crystallite size in composite system (table 1) was also estimated using the well-known Debye-Scherrer relation (Cullity 1978). This too shows an enhancement in amorphous behaviour of composite electrolytes up to $6 \mathrm{wt} \% \mathrm{Al}_{2} \mathrm{O}_{3}$ concentration and thereafter it decreases, i.e. improvement in crystalline behaviour. All these results clearly indicate improvement in system morphology up to $6 \mathrm{wt} \%$ filler addition.

\subsection{DSC studies}

DSC thermograms of figure 3, represent the thermal scans for pure PVA (scan a), $\mathrm{NH}_{4} \mathrm{SCN}$ (scan b), $\mathrm{Al}_{2} \mathrm{O}_{3}$ nanofiller (scan c) and PVA : $\mathrm{NH}_{4} \mathrm{SCN}$ : DMSO electrolyte (scan d) along with a few nano-filled composite gel electrolytes. It is well established that both crystalline and amorphous phases coexist in most of the polymers
(Tager 1978; Bhat and Deshmukh 2002). PVA is a partially crystalline polymer which exhibits both the glass transition and melting transition. The glass transition temperature and melting temperature of PVA is seen to occur at 88 and $216^{\circ} \mathrm{C}$, respectively (scan b). These transitions are in close proximity to the earlier reported values (Gong et al 1989; Shukla and Agrawal 2000). A broad shoulder peak around $170^{\circ} \mathrm{C}$ is also witnessed in the DSC profile of pure PVA. Such a feature has also been reported earlier (Zou et al 2008) and ascribed to phenton melting (Mukherjee et al 2004). DSC thermogram for pristine gel electrolyte used in the development of composite system has also been recorded (scan d). In consonance with earlier reports (Shukla and Agrawal 2000; Awadhia and Agrawal 2007), pristine electrolyte thermogram (scan d) depicts four endothermic transitions including two small shoulders related to phenton melting, PVA : $\mathrm{NH}_{4} \mathrm{SCN}$ : DMSO complex and uncomplexed PVA, respectively. Since composite polymer gel electrolytes are characterized by salt solution (liquid electrolyte) trapped within the polymer network, the thermal behaviour of polymer composite gel electrolytes is expected to be affected by the interaction between components present in it. On adding $2 \mathrm{wt} \%$ of $\mathrm{Al}_{2} \mathrm{O}_{3}$ nanoparticles in pristine gel electrolyte to form composite gel electrolyte, the melting point of salt and PVA appears in the temperature range $433-513 \mathrm{~K}$ (scan e) in addition to the broadness in endothermic transitions (Shukla and Agrawal 
Table 1. Average crystallites size, crystilinity, ionic transference number and activation energy of as-synthesized composite gel electrolyte system (PVA : DMSO : $\mathrm{NH}_{4} \mathrm{SCN}: \mathrm{Al}_{2} \mathrm{O}_{3}$ ).

\begin{tabular}{lccccc}
\hline $\begin{array}{l}\text { Sl. } \\
\text { no. }\end{array}$ & $\begin{array}{c}\text { Concentration of } \mathrm{Al}_{2} \mathrm{O}_{3} \text { content } \\
\text { in Pristine electrolyte }(\mathrm{wt} \%)^{\mathrm{a}}\end{array}$ & $\begin{array}{c}\text { Average crystallites } \\
\text { size }(\mathrm{nm})\end{array}$ & $\begin{array}{c}\text { Crystallinity, } \\
X_{\mathrm{c}}(\%)\end{array}$ & $\begin{array}{c}\text { Ionic transference } \\
\text { number, } t_{\text {ion }}\end{array}$ & $\begin{array}{c}\text { Activation energy, } \\
E_{\mathrm{a}}(\mathrm{eV})^{\mathrm{c}}\end{array}$ \\
\hline 1 & 0 & $\sim 45$ & 65.9 & 0.94 & 0.081 \\
2 & 4 & $\sim 38$ & 46.3 & 0.96 & 0.058 \\
3 & 2 & $\sim 37$ & $32 \cdot 2$ & 0.98 & 0.047 \\
4 & 8 & $\sim 42$ & 44.8 & 0.97 & 0.053 \\
5 & 10 & $\sim 41$ & 72.7 & 0.95 & 0.083 \\
\hline
\end{tabular}

${ }^{\mathrm{a}}$ Pristine electrolyte (prepared by adding $5 \mathrm{wt} \%$ PVA in $1 \mathrm{M} \mathrm{NH}_{4} \mathrm{SCN}$ salt solution in DMSO).

${ }^{\mathrm{b}}$ Ionic transference number calculated using relation (i).

${ }^{\mathrm{c}}$ Activation energy calculated from $\log \sigma$ vs $1000 / T$ plot (figure 8) in Arrhenius region.

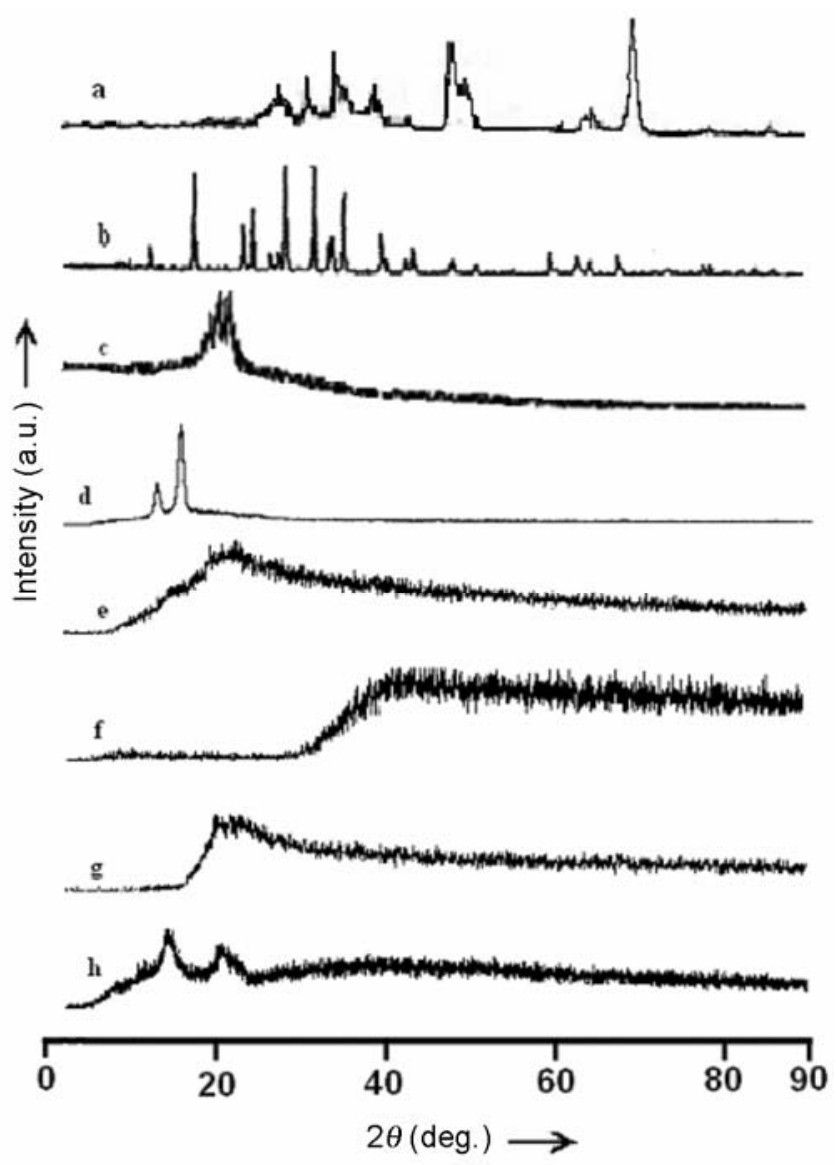

Figure 2. X-ray diffractograms of (a) $\mathrm{Al}_{2} \mathrm{O}_{3}$ nanoparticles, (b) $\mathrm{NH}_{4} \mathrm{SCN}$, (c) DMSO casted PVA gel film (d) DMSO casted PVA: $\mathrm{NH}_{4} \mathrm{SCN}$ gel electrolyte and its composite containing (e) $4 \mathrm{wt} \%$, (f) $6 \mathrm{wt} \%$, (g) $8 \mathrm{wt} \%$ and (h) $10 \mathrm{wt} \% \mathrm{Al}_{2} \mathrm{O}_{3}$ filler.

2000; Awadhia and Agrawal 2007). The observed broadness results from coexistence of uncomplexed salt $\left(\mathrm{NH}_{4} \mathrm{SCN}\right), \mathrm{PVA}$ : $\mathrm{NH}_{4} \mathrm{SCN}$ complex, excess DMSO and uncomplexed PVA-related endothermic transitions. The presence of partially complexed component PVA : $\mathrm{NH}_{4} \mathrm{SCN}$ is also visible in the DSC thermogram of gel films containing higher filler content $\left(4 \mathrm{wt} \%\right.$ and $6 \mathrm{wt} \% \quad \mathrm{Al}_{2} \mathrm{O}_{3}$ nanoparticle, viz. scans $\mathrm{f}$ and $\mathrm{g}$ ). DSC thermograms further indicate a strong endothermic transition around $430 \mathrm{~K}$ which shifts to higher temperature on addition of nanofiller up to $4 \mathrm{wt} \%$. Such a shift may be due to encapsulation of system and attachment of methyl group of DMSO with polar group of PVA, leading to gelification. The retrieval of this transition at $6 \mathrm{wt} \%$ can be attributed to agglomeration of nanoparticles as also seen in XRD and SEM analysis.

\subsection{Wagner's polarization}

Figure 4 depicts the Wagner's polarization curves for two composite gel electrolyte samples. The ionic transference number $t_{\text {ion }}$ was evaluated using the following relation:

$$
t_{\text {ion }}=\frac{I_{\text {initial }}-I_{\text {final }}}{I_{\text {initial }}}=\frac{I_{\text {total }}-I_{\text {electronic }}}{I_{\text {total }}}=\frac{I_{\text {ionic }}}{I_{\text {total }}},
$$

where $I_{\text {ionic }}$ is the current due to ions, $I_{\text {electronic }}$ (or $I_{\text {final }}$ ) the current due to electrons, and $I_{\text {total }}$ (or $I_{\text {initial }}$ ) the sum of ionic and electronic contribution to current.

It is observed that the nature of charge transport is similar to that for solvent-free gel polymeric electrolytes (Shukla and Agrawal 2000). Moreover, the charge transport appears to exist when mobile ions are trapped within the polymer-matrix complex. It is noticed from table 1 that $t_{\text {ion }}$ gradually increases (up to 0.98) upon addition of $\mathrm{Al}_{2} \mathrm{O}_{3}$ nanoparticles up to $6 \mathrm{wt} \%$ and thereafter it decreases. Such a behaviour can be associated to loss of ionic conductivity after adding more than $6 \mathrm{wt} \%$ of $\mathrm{Al}_{2} \mathrm{O}_{3}$ nanoparticles in PVA gel electrolytes.

\subsection{Conductivity studies}

Figure 5 shows the effect of salt concentration on ionic conductivity of $\mathrm{Al}_{2} \mathrm{O}_{3}$ nanoparticles-filled PVA : $\mathrm{NH}_{4} \mathrm{SCN}$ : DMSO polymer gel electrolytes. Conductivity of composite gel electrolyte samples has been extracted with the help of $Z^{\prime}$ versus $Z^{\prime \prime}$ data. Agrawal and Awadhia (2004) have recently reported the effect of salt variation on ionic conductivity of DMSO : $\mathrm{NH}_{4} \mathrm{SCN}$ : PVA gel 
electrolytes. It has been shown that complex formation takes place in the system, which tends to raise the conductivity of the system through greater dissociation of salts. Upon dispersal of $4 \mathrm{wt} \% \quad \mathrm{Al}_{2} \mathrm{O}_{3}$ nanoparticles in pristine gel electrolyte to form nanocomposite gel electrolyte, the bulk conductivity is seen to rise with salt molarity and attain an optimum at $1 \mathrm{M}$ salt concentration. This conductivity behaviour corresponds to that for liquid electrolyte although the magnitude is lower for optimum conductivity (Patel et al 2007). This correspondence of conductivity response reflects the presence of trapped liquid electrolyte within polymer matrix, which affects the conductivity of composite system. It has been shown earlier in morphological studies (figure 1) that upon addition of $\mathrm{Al}_{2} \mathrm{O}_{3}$ nanoparticles in pristine electrolytes, they get entrapped within the chains in the pores. This affects the solvent holding capacity of matrix electrolyte and hence the conductivity. Thus, when the polymer and nano-

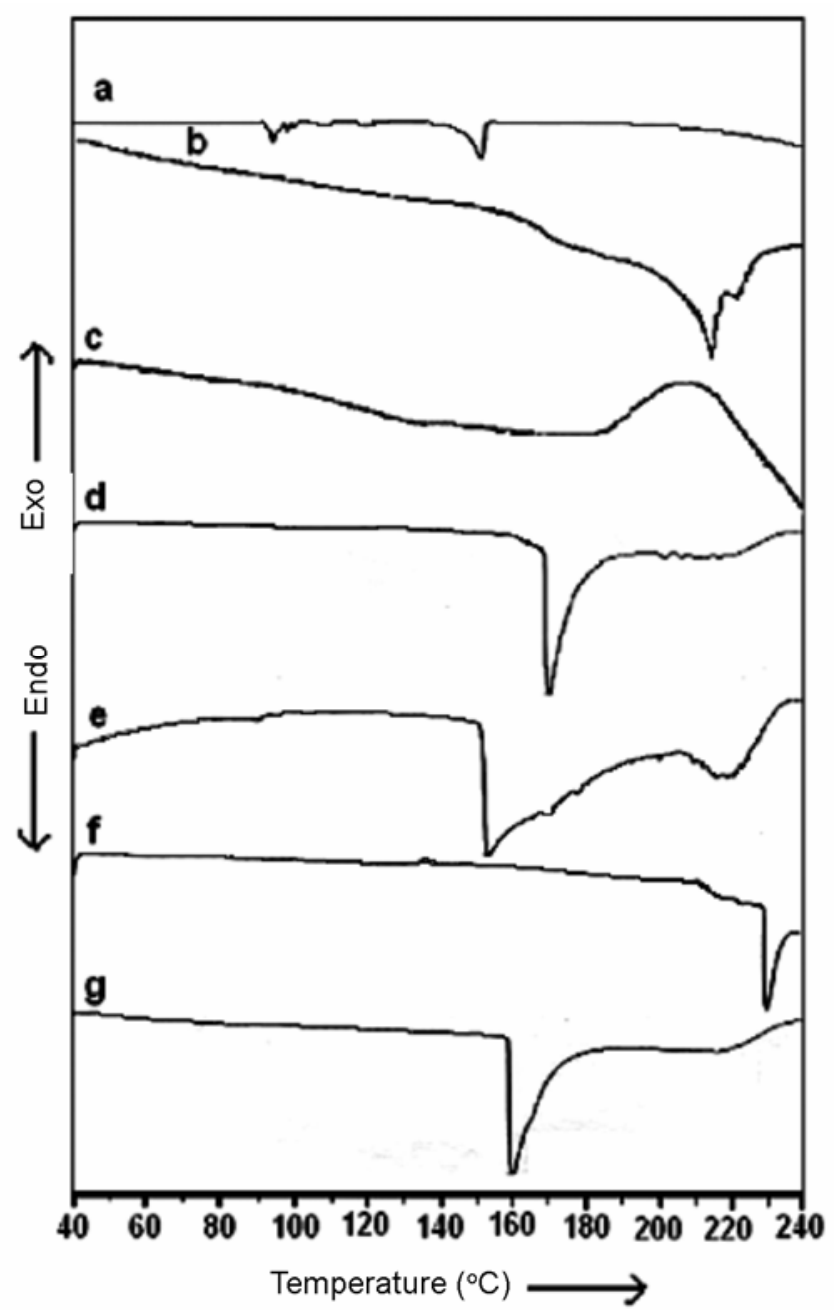

Figure 3. DSC diffractograms of (a) $\mathrm{NH}_{4} \mathrm{SCN}$, (b) PVA, (c) $\mathrm{Al}_{2} \mathrm{O}_{3}$ nano particles, (d) DMSO casted PVA : $\mathrm{NH}_{4} \mathrm{SCN}$ gel electrolyte film and its composite containing (e) $2 \mathrm{wt} \%$, (f) $4 \mathrm{wt} \%$ and $(\mathrm{g}) 6 \mathrm{wt} \% \mathrm{Al}_{2} \mathrm{O}_{3}$ nanofiller. filler components are present in a composite gel system, the polymer matrix not only works as stiffener but also affects ionic conduction. At lower concentrations of salt, full dissociations of salt into respective ions may be considered and there is nothing to be dissociated by the

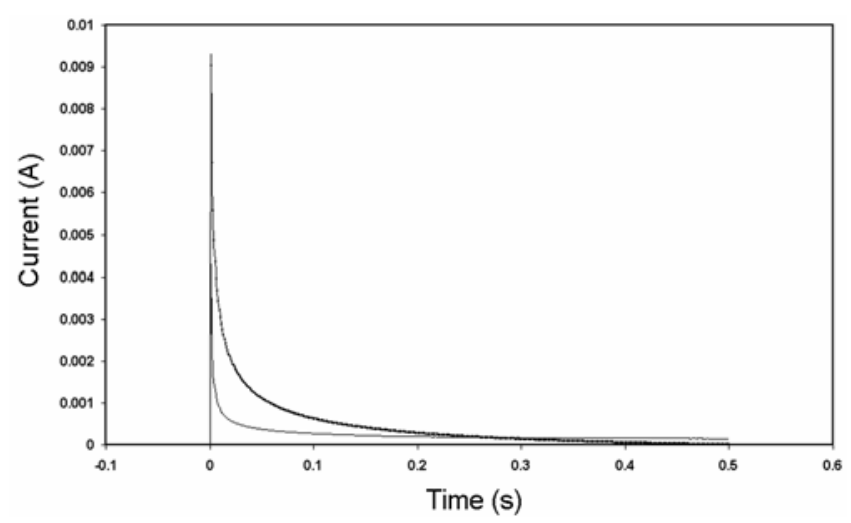

Figure 4. I- $t$ polarization curve of polymer composite electrolytes with (------) $0 \mathrm{wt} \%$ and $(\bullet) 6 \mathrm{wt} \% \mathrm{Al}_{2} \mathrm{O}_{3}$ filler.

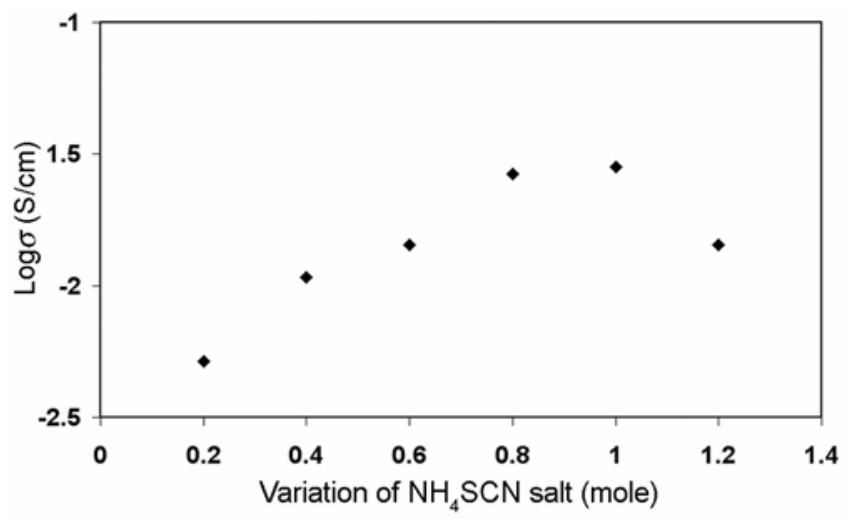

Figure 5. Variation of conductivity of polymer nanocomposite gel electrolytes with $\mathrm{NH}_{4} \mathrm{SCN}$ salt concentration (at room temperature).

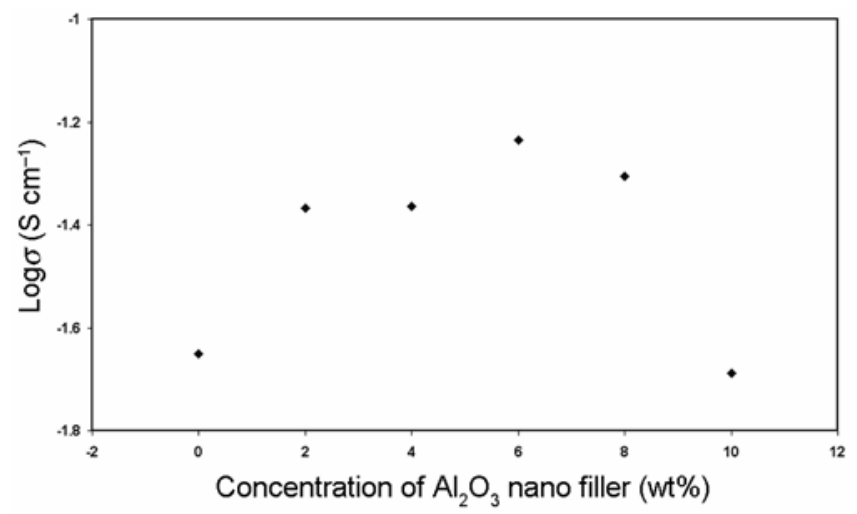

Figure 6. Variation of conductivity of polymer nanocomposite gel electrolytes with $\mathrm{Al}_{2} \mathrm{O}_{3}$ filler concentration (at room temperature). 
polymer. Therefore as the concentration of salt enhances concentration of free ions increases and so the conductivity increases in accordance with the relation:

$$
\sigma=n q \mu,
$$

where $q$ represents the charge of mobile carrier, $n$ the charge carrier concentration and $\mu$ the carrier mobility.

Increase in the amount of salt content leads to increase in fraction of undissociated salt in gel solution. However, the polymer-salt interaction, as reported earlier (Awadhia and Agrawal 2007) and witnessed in XRD studies (figure 2 ), tends to promote greater dissociation of salt. This in tantamount to higher conductivity values in accordance with relation (ii). For very high salt contents ( $>1 \mathrm{M}$ concentration) dissociation of salt by polymer is restricted by further increase in fraction of undissociated salt in gel solution, which raises the viscosity of gel system and hence conductivity decreases.

Figure 6 shows the role of $\mathrm{Al}_{2} \mathrm{O}_{3}$ nanoparticles concentration on ionic conduction of polymer gel electrolytes. In the presence of filler, conductivity is seen to

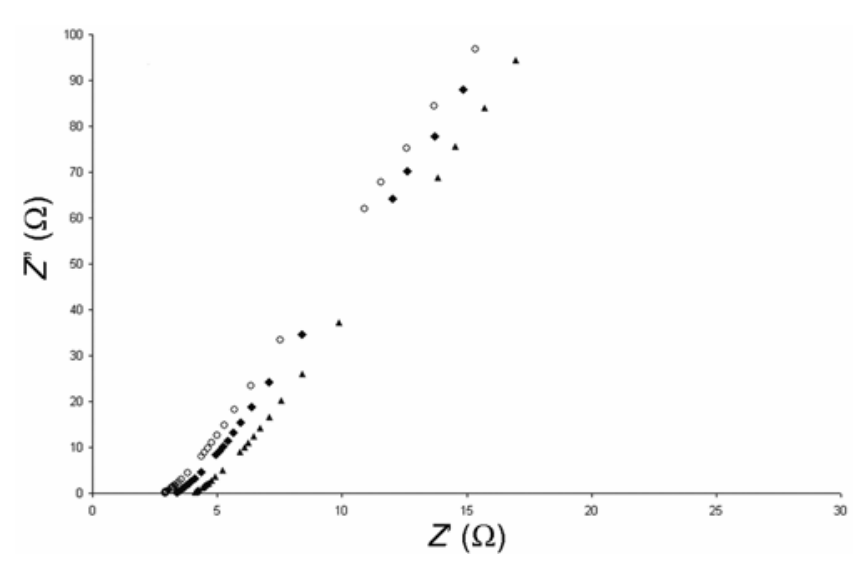

Figure 7. Temperature dependence of the complex impedance spectra of polymer composite electrolytes containing $6 \mathrm{wt} \%$ $\mathrm{Al}_{2} \mathrm{O}_{3}$ nanofiller at $(\boldsymbol{\Delta}) 306,(\bullet) 316$ and $(\mathrm{O}) 326 \mathrm{~K}$.

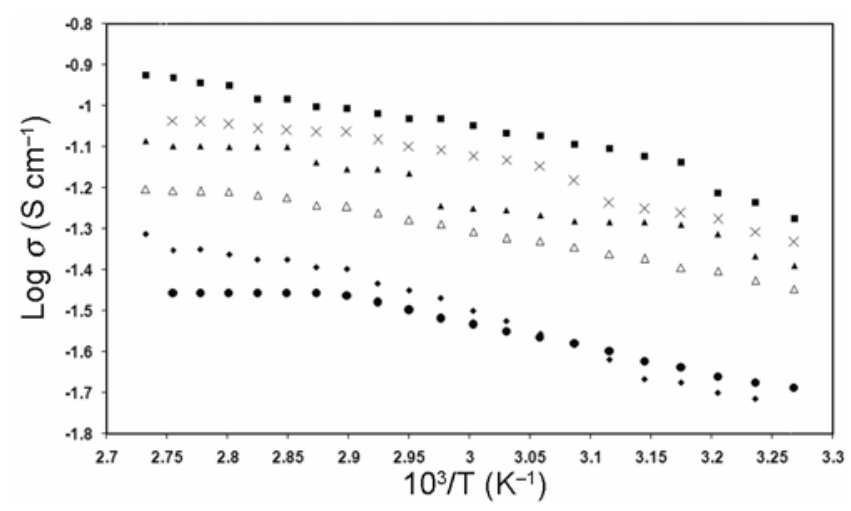

Figure 8. Temperature dependence conductivity of polymer nanocomposite gel electrolytes with $(\bullet) 0 \mathrm{wt} \%,(\boldsymbol{\Delta}) 2 \mathrm{wt} \%,(\Delta)$ $4 \mathrm{wt} \%$, (घ) $6 \mathrm{wt} \%,(\times) 8 \mathrm{wt} \%$ and $(\bullet) 10 \mathrm{wt} \% \mathrm{Al}_{2} \mathrm{O}_{3}$ filler content. increase by an order of magnitude. Closer examination of conductivity behaviour shows two maximas, one around $2 \mathrm{wt} \%$ and the other around $6 \mathrm{wt} \%$ filler concentration a feature typical of nanocomposite polymer gel electrolytes (Pandey et al 2008). At low filler concentration, greater dissociation of salt and increase in amorphous behaviour (XRD studies) tends to enhance free ions concentration and mobility, which significantly enhances ionic conductivity. A flattening in conductivity response is noticed beyond $2 \mathrm{wt} \% \mathrm{Al}_{2} \mathrm{O}_{3}$ contents. This can be associated to the fact that all the salt has been dissociated and so charge carrier concentration is limited. It is only the change in system morphology that tends to affect the conductivity, and thus, again, an enhancement of small magnitude is visible. In situations when there is very large quantity of nanoparticles (beyond $6 \mathrm{wt} \%$ ) present in the composite system, agglomeration of these nanoparticles takes place, which leads to decrease in conductivity due to creation of tortuous pathways for mobile ions. Another factor that can be associated with the fall in conductivity beyond $6 \mathrm{wt} \%$ filler content is the increase in microscopic viscosity of the composite system. Thus, an optimum in conductivity was found $\left(5.81 \times 10^{-2} \mathrm{~S} / \mathrm{cm}\right)$ for $6 \mathrm{wt} \%$ of $\mathrm{Al}_{2} \mathrm{O}_{3}$ nanoparticles.

\subsection{Temperature dependence of conductivity}

Figure 7 shows the temperature dependence of complex impedance spectra of composite gel electrolyte samples, and figure 8 shows the temperature dependence of conductivity of composite gel electrolytes in $1 \mathrm{M} \mathrm{NH}_{4} \mathrm{SCN}$ and $5 \mathrm{wt} \%$ PVA for different wt $\%$ of nano-sized $\mathrm{Al}_{2} \mathrm{O}_{3}$. All the curves display similar behaviour, i.e. a combination of Arrhenius and VTF behaviour, with the former being noticed in the low-temperature region and later at higher temperatures. The low-temperature Arrhenius behaviour is on account of the presence of liquid electrolyte encapsulated by the blend matrix, i.e. effect of temperature on conductivity of liquid electrolytes. As the temperature of system is raised beyond $314 \mathrm{~K}$, segmental motion of polymer in polymer composite comes into play and starts affecting the conductivity, leading to VTF nature described by the following relation:

$$
\sigma=\sigma_{0 \exp }\left(\frac{-B}{T-T_{0}}\right),
$$

where $\sigma_{0}$ is the pre-exponential factor, $B$ a constant related to activation energy and $T_{0}\left(T_{\mathrm{g}}-60^{\circ}\right)$ is quasiequilibrium glass transition temperature.

A low value of activation energy in low temperature region (table 1) has been observed. Such low values are typically observed for polymer gel electrolytes. Lowering of activation energy till $6 \mathrm{wt} \% \quad \mathrm{Al}_{2} \mathrm{O}_{3}$ content reaffirms improvement in ionic conduction in the presence of nanosized fillers in polymer gel electrolytes. 


\subsection{CV studies}

Figure 9 compares cyclic voltagrams of the PVA gel electrolyte systems having different concentrations of $\mathrm{Al}_{2} \mathrm{O}_{3}$ nanofiller. It is apparent from this figure that the electrochemical stability is moderately good without any filler which ranges from -1.2 to $+1.4 \mathrm{~V}$. On addition of the nanofiller, the stability is seen to improve $(-1 \cdot 3$ to $+1.4 \mathrm{~V})$. Another effect of adding the nanofiller is the narrowing of faradic currents during oxidation and reduction cycles in the stable region. A stable potential window is of great practical importance for applications in batteries and super capacitors as it determines the maximum operating voltage of a capacitor (Kubota et al 2000, 2002; Kim et al 2002). An interesting observation is the appearance of a single oxidation/reduction peak for

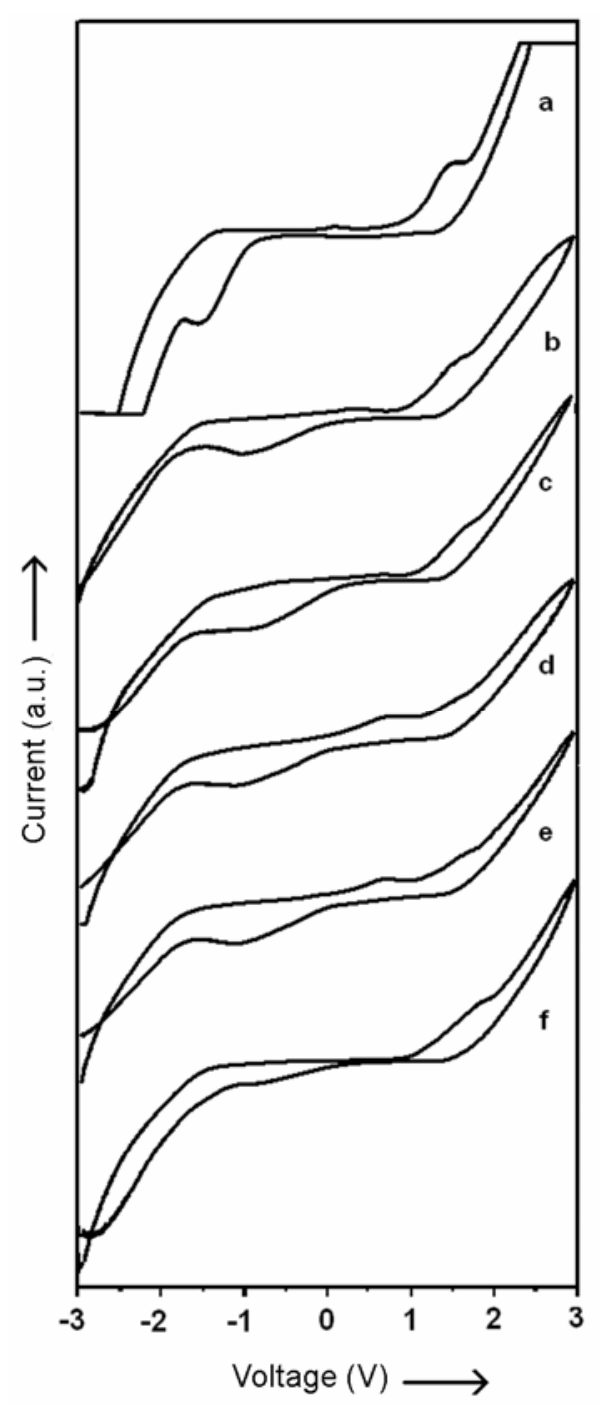

Figure 9. Cyclic voltagrams of (a) DMSO casted PVA: $\mathrm{NH}_{4} \mathrm{SCN}$ gel film and its composite containing (b) $2 \mathrm{wt} \%$, (c) $4 \mathrm{wt} \%$, (d) $6 \mathrm{wt} \%$, (e) $8 \mathrm{wt} \%$ and (f) $10 \mathrm{wt} \% \mathrm{Al}_{2} \mathrm{O}_{3}$ filler content. all pristine and composite gel electrolytes, which is possibly on account of $\mathrm{NH}_{4}^{+}$ion that contributes to ionic conduction. In the presence of the filler, the reduction peak was noticed to shift on the potential scale along with decrease in the intensity before virtually vanishing in the presence of electrolytes containing $10 \mathrm{wt} \%$ filler. These studies indicate improvement in electrochemical stability of nanocomposite gel electrolyte in the presence of $\mathrm{Al}_{2} \mathrm{O}_{3}$ fillers. Optimum electrochemical window was observed to be $\pm 1.65 \mathrm{~V}$ for composite gel electrolytes containing $6 \mathrm{wt} \% \mathrm{Al}_{2} \mathrm{O}_{3}$ filler.

\section{Conclusion}

$\mathrm{Al}_{2} \mathrm{O}_{3}$ nanoparticles-filled polymer gel electrolytes of PVA : DMSO : $\mathrm{NH}_{4} \mathrm{SCN}$ have been successfully synthesized by solution cast technique. XRD patterns exhibit broadening of diffraction patterns of composite on addition of $\mathrm{Al}_{2} \mathrm{O}_{3}$ nanofillers up to $6 \mathrm{wt} \%$, suggesting improved amorphousness. SEM images show formation of uniform dispersed phase in composites. Bulk conductivity of synthesized samples increases by an order of magnitude with increasing amount of $\mathrm{Al}_{2} \mathrm{O}_{3}$ nanofillers up to $6 \mathrm{wt} \%$ of filler content. Maximum absorption of the nanofiller is found to be $6 \mathrm{wt} \%$. Addition of $\mathrm{Al}_{2} \mathrm{O}_{3}$ nanofillers provides electrochemical current stability to PVA gel electrolyte. All these results indicate possible application of PVA : DMSO : $\mathrm{NH}_{4} \mathrm{SCN}: \mathrm{Al}_{2} \mathrm{O}_{3}$ gel electrolytes in super capacitors, polymer membranes, fuel cells and smart windows. Further studies are underway to establish this.

\section{References}

Agrawal R C and Pandey G P 2008 J. Phys. D: Appl. Phys. 41 223001

Agrawal S L and Awadhia A 2004 Bull. Mater. Sci. 27523

Agrawal S L and Shukla P K 2000 J. Pure Appl. Phys. 3853

Awadhia A and Agrawal S L 2007 Solid State Ionics 178951

Bhat N V and Deshmukh R R 2002 J. Pure Appl. Phys. 40361

Bohnke O, Rousselot C, Gillet P A and Truche C 1992 J. Electrochem. Soc. 139

Caravanier C C, Montigny B C, Lemordant D and Bosser G 2003 Solid State Ionics 156113

Cavalieri F, Chiessi E, Spagnoti C and Cowman M K 2003 J. Mater. Sci. Mater. Med. 14687

Chandra S, Sekhon S S and Arora N 2000 Ionics 6112

Colomban P (ed.) 1992 Proton conductors: solids, membranes and gels-materials and devices (Cambridge: Cambridge university Press)

Croce F, Gerace F, Dautzemberg G, Passerini S, Appetechi G B and Scrosati B 1994 Electrochim. Acta 392187

Cullity B D (ed.) 1978 Elements of X-ray diffraction (London: Addition-Wesley Publishing Company Inc.) 2nd edn, pp. 281-286

Duangkaew P and Woothikanokkhan J 2008 J. Appl. Polym. Sci. 109452 
Finch C A (ed.) 1973 Polyvinyl alcohol: properties and applications (Bristol: John Wiley \& Sons)

Gong K C, Cai H S, Nazri G, Huggins R A and Shriver D F (eds) 1989 Solid State Ionics (Pittsburgh: Materials Research Society) Vol. 135, p. 377

Gray F M 1991 Solid polymer electrolytes-fundamental and technological applications (New York: VCH)

Honma I, Hirakava S, Yamada and Bae J M 1999 Solid State Ionics 11829

Kim K M, Park N G, Ryu K S and Chang S H 2002 Polymer 43 3951

Koksbang R, Oslen I I and Shackle D 1994 Solid State Ionics 69320

Kubota N, Watanabe H, Konaka G and Eguchi Y $2000 \mathrm{~J}$. Appl. Polym. Sci. 7612

Kubota N, Fujii S, Tatsumoto N and Sano T 2002 J. Appl. Polym. Sci. 832655

MacCallum J R and Vincent C A (eds) 1989 Polymer electrolyte reviews (London: Elsevier Applied Sciences Publisher) pp. 1-2

Mukherjee G S, Shukla N, Singh R K and Mathur G N 2004 J. Sci. Ind. Res. 63596
Pandey K, Dwivedi M M, Tripathi M, Singh M and Agrawal S L 2008 Ionics 14515

Patel S K, Patel R B, Awadhia A, Chand N and Agrawal S L 2007 Pramana 69467

Radhucha D, Wieczorek W, Florjanczyk Z and Stevens J R 1996 J. Phys. Chem. 10020126

Ray S S and Okamoto M 2003 Prog. Polym. Sci. 281539

Sato T, Bonno K, Maruo T and Nozu R 2005 J Power Sources 152264

Scrosati B and Vincent C A 2000 M R S Bull. 28

Sekhon S S 2003 Bull. Mater. Sci. 26321

Sekhon S S, Arora N, Singh B and Chandra S 2002 J. Mater. Sci. 372159

Shukla P K and Agrawal S L 2000 Ionics 6312

Singh H P, Kumar R and Sekhon S S 2005 Bull. Mater. Sci. 128467

Song J Y, Wang Y Y and Wan C C 2000 J. Electrochem. Soc. 1473219

Tager A (ed.) 1978 Physical chemistry of polymers (Moscow: MIR Publishers)

Wieczorek W, Florjanczyk Z and Stevens J R 1995 Electrochim. Acta $\mathbf{4 0} 2327$

Zou G X, Jin P Q and Xin L Z 2008 J. Elastomers Plastics 40303 